\title{
Effect of Different Types of Upper Instrumented Vertebrae Instruments on Proximal Junctional Kyphosis Following Adult Spinal Deformity Surgery: Pedicle Screw versus Transverse Process Hook
}

\author{
Akira Matsumura ${ }^{1}$, Takashi Namikawa ${ }^{1}$, Minori Kato $^{1}$, Shoichiro Oyama ${ }^{1}$, \\ Yusuke Hori ${ }^{1}$, Akito Yabu ${ }^{1}$, Noriaki Hidaka ${ }^{1}$, Hiroaki Nakamura ${ }^{2}$ \\ ${ }^{I}$ Department of Orthopaedic Surgery, Osaka City General Hospital, Osaka, Japan \\ ${ }^{2}$ Department of Orthopaedic Surgery, Osaka City University Graduate School of Medicine, Osaka, Japan
}

Study Design: Retrospective comparative study.

Purpose: To compare the incidence of proximal junctional kyphosis (PJK) between transverse process hooks (TPHs) and pedicle screws (PSs) at the upper instrumented vertebrae (UIV) following adult spinal deformity (ASD) surgery.

Overview of Literature: The choice of UIV implant type may be important for avoiding PJK; however, few comparative clinical studies have evaluated the incidence of PJK according to the type of UIV implant used in ASD surgery.

Methods: We retrospectively reviewed 39 consecutive patients with ASD (mean age, 67 years; mean follow-up period, 41 months) who underwent corrective surgery between 2009 and 2013. TPH was used in 17 patients and PS in 22 patients. PJK was defined as the presence of a UIV or UIV \pm 1 fracture, or a change in the proximal junctional angle (PJA) of $>20^{\circ}$. Data of patients with $T P H$ and PS were compared.

Results: The TPH group had a PJK incidence of $17.6 \%$ compared with $27.3 \%$ in the PS group ( $p=0.47)$. In the TPH group, PJK was a result of UIV fracture in one patient, UIV-1 fracture in one patient, and ligamentous failure in one patient. In the PS group, six patients developed PJK because of UIV fracture. No differences in radiographic parameters were found between the two groups. After analyzing the PJA data in the patients with PJK, the changes in PJA were significantly higher in the PS group than in the TPH group $\left(19.0^{\circ} / 5.0^{\circ}, p=0.04\right)$.

Conclusions: Our results show that using TPH as a UIV implant may not prevent PJK; however, using TPH as the UIV anchor may prevent vertebral collapse if cases of UIV fracture. The increased risk of UIV fracture collapse in the PS group may be a result of a higher mechanical load on UIV when using PS.

Keywords: Adult spinal deformity; Proximal junctional kyphosis; Transverse hook; Pedicle screws

Received Oct 15, 2017; Revised Nov 29, 2017; Accepted Dec 21, 2017

Corresponding author: Akira Matsumura

Department of Orthopaedic Surgery, Osaka City General Hospital, 2-13-22 Miyakojimahondori, Miyakojima-ku, Osaka 534-0021, Japan Tel: +81-6-6929-1221, Fax: +81-6-6929-1091, E-mail: amatsumura@med.osaka-cu.ac.jp 


\section{Introduction}

Surgical intervention for an adult spinal deformity (ASD) is mainly aimed at correcting the spinopelvic malalignment and subsequently restoring the global sagittal balance [1]. To achieve spinal balance, surgical long-segment fixation to the pelvis is often necessary $[2,3]$. However, long-segment spinal fixation, particularly to the pelvis, is associated with the potential risks of postoperative complications including pseudoarthrosis [4], implant failure $[5,6]$, and adjacent problems $[7,8]$. Proximal junctional kyphosis (PJK) is an important concern with ASD surgery $[7,8]$. PJK following ASD surgery is reported in approximately $30 \%$ of cases [8] and may result in poor clinical outcomes [9] or neurological problems [10,11]. Several reports found that possible risk factors were long and rigid fusion constructs and pedicle screw (PS) instrumentation techniques [11,12], upper instrumented vertebrae (UIV) $[13,14]$, integrity of the posterior soft-tissue tension band $[15,16]$, magnitude of the correction in the sagittal plane $[17,18]$, combined anteroposterior (AP) spinal surgery [19], and osteoporosis [20].

Some previous reports that targeted adolescent idiopathic scoliosis described the possibility of the implant type at UIV in spinal deformity surgery as a factor in the development of PJK $[21,22]$. To avoid PJK, it is thought that the type of UIV implant may be important; however, few comparative clinical studies have evaluated the incidence of PJK according to the type of UIV implant in ASD surgery. The aim of this study is to compare the incidence of PJK and changes in the proximal junctional angle (PJA) following ASD surgery using two types of UIV implants: transverse process hooks (TPHs) and PSs.

\section{Materials and Methods}

The medical records of 39 consecutive patients (two men and 37 women) with ASD who underwent corrective surgery by a single surgeon at a single institution and were followed up for at least 2 years were retrospectively reviewed. The mean age at the time of surgery was 67.4 years (range, $42-83$ years), and the average follow-up period was 42.9 months (range, 24-91 months). All patients complained of multiple years of lower back pain that was not alleviated with conservative treatment. T9 UIV was selected in 13 patients and T10 UIV in 26 patients. Spinopelvic fusion was performed in all patients using iliac or sacral-alar-iliac screws. PSs as UIV implants were used in the first 22 patients until 2013, and TPHs were used in the next 17 patients from 2013 onward. Sublaminar taping with two polyethylene tapes at UIV was also used in all patients. Augmentation by sublaminar taping at UIV was an effective method of preventing the pull-out of spinal instruments, including TPH and PS. It also added semirigid stabilization by holding the entire lamina. Among the 39 patients, 10 patients underwent three-column osteotomy (pedicle subtraction osteotomy or vertebral column resection).

The following radiographic parameters were assessed with standing AP and lateral plain radiography immediately prior to surgery (PreO), 2 weeks after surgery (PO), and 2 years after surgery (PO2Y): degree of thoracic kyphosis (TK, T5-T12), degree of thoracolumbar kyphosis (TLK, T10-L2), degree of lumbar lordosis (LL, T12- S1), pelvic tilt (PT), pelvic incidence (PI), sagittal vertical axis (SVA), Cobb angle of the lumbar curve (L-curve), and coronal vertical axis. Each patient's curve flexibility was also evaluated with side bending (L-curve flexibility) films in the coronal plane and with fulcrum backward bending (FBB) films in the sagittal plane [23]. PJA was measured between the caudal endplate of UIV to the cephalad endplate located two vertebrae proximal, as previously described by Glattes et al. [24].

PJK was defined by two criteria: (1) UIV, UIV+1, and UIV-1 vertebral fracture, and (2) change in PJA (dPJA) of at least $20^{\circ}$ compared with the preoperative measurement. Using all data, two comparative analyses were performed: (1) between PJK and non-PJK groups and (2) between TPH and PS groups.

Clinical outcomes were evaluated using the Japanese

Table 1. Surgical outcome data of all patients; Japanese version of the Scoliosis Research Society-22 Outcomes Questionnaire

\begin{tabular}{lcccccc} 
Variable & Function/activity & Pain & Self image & Mental health & Total score & Satisfaction \\
\hline Prior to surgery & 2.7 & 2.7 & 2.2 & 2.6 & 2.5 & - \\
\hline 2 Years after surgery & 3.8 & 4.1 & 3.7 & 3.8 & 3.8 & 4.1 \\
\hline$p$-value & $<0.0001$ & $<0.0001$ & $<0.0001$ & $<0.0001$ & $<0.0001$ & - \\
\hline
\end{tabular}


editions of the Scoliosis Research Society-22 Outcomes Questionnaire (SRS-22) and the Medical Outcomes Study Questionnaire Short-Form 36 (SF-36) administered at $\mathrm{PreO}$ and PO2Y. All data were statistically analyzed using analysis of variance, Mann-Whitney $U$-test, or paired or unpaired $t$-test as appropriate (JMP ver. 11.0; SAS, Cary, NC, USA). For all tests, $p<0.05$ was considered statistically significant.

This study was approved by the ethics committee of Osaka City General Hospital (approval no., 1305011).

\section{Results}

\section{Clinical outcomes}

The mean total SRS- 22 scores were $2.5 \pm 0.7$ at PreO, which significantly improved to $3.8 \pm 0.5$ at $\mathrm{PO} 2 \mathrm{Y}(p<0.0001)$. The mean overall patient satisfaction scores were 4.1 (range, 2.5-5.0), indicating a good surgical outcome. All domains of SRS-22 significantly improved at PO2Y (Table 1). Table 2 shows health-related quality of life data measured by SF36. All domains of SF-36 significantly improved at PO2Y $(p<0.05)$.

\section{Radiographic evaluation}

The mean values of the preoperative radiographic parameters in the sagittal plane were as follows: TK, $15.4^{\circ}$; TLK, $17.5^{\circ}$; LL, $11.5^{\circ}$; PT, $32.9^{\circ}$; PI, 52.3 ; and SVA, $104.6 \mathrm{~mm}$. The preoperative mean PI-LL was $40.4^{\circ}$. PI-LL in FBB films was $18.2^{\circ}$. PI-LL was reduced to $3.3^{\circ}$ at $\mathrm{PO}$ and increased to $5.2^{\circ}$ at $\mathrm{PO} 2 \mathrm{Y}$. PT improved was to $20.9^{\circ}$ at $\mathrm{PO}$ and remained stable at PO2Y. SVA also improved to 26.1 $\mathrm{mm}$ at $\mathrm{PO}$, but increased to $39.0 \mathrm{~mm}$ at $\mathrm{PO} 2 \mathrm{Y}$, although the change was not significant (Table 3 ).

$\mathrm{PJK}$ occurred in nine patients, three in the TPH group and six in the PS group. The incidence of PJK in the two groups was not significantly different $(p=0.47)$. In the TPH group, PJK was caused by UIV fracture in one patient, UIV-1 fracture in one patient, and ligamentous failure resulting in $\mathrm{dPJA}>20^{\circ}$ in one patient. In six patients in the PS group (66.7\%), PJK was caused by UIV fracture that occurred within 4 weeks after surgery.

Table 2. Surgical outcome data of all patients; health-related quality of life outcomes measured with the Medical Outcomes Study Questionnaire Short-Form 36

\begin{tabular}{lcccccccc} 
Variable & PF & RP & BP & GH & VT & SF & RE & MH \\
\hline Prior to surgery & 42.4 & 40.2 & 37.1 & 42.5 & 39.8 & 52.5 & 49.5 & 49.1 \\
\hline 2 Years after surgery & 64.3 & 71.0 & 60.4 & 59.5 & 60.7 & 74.3 & 73.7 & 70.0 \\
\hline$p$-value & 0.0005 & $<0.0001$ & $<0.0001$ & 0.0006 & 0.0001 & 0.002 & 0.001 & $<0.0001$ \\
\hline
\end{tabular}

${ }^{a}$ The Short-Form 36 comprises eight health scales: physical functioning (PF), role limitations caused by physical problems (RP), bodily pain (BP), general health perceptions (GH), vitality (VT), social functioning (SF), role limitations caused by emotional problems (RE), and mental health (MH).

Table 3. Radiographic measurements made in the sagittal plane

\begin{tabular}{|c|c|c|c|c|c|}
\hline Variable & Prior to surgery & 2 Weeks after surgery & $p$-value & 2 Years after surgery & $p$-value \\
\hline Thoracic kyphosis $\left({ }^{\circ}\right)$ & 15.4 (-15 to 50$)$ & 27.4 (5 to 53$)$ & $<0.0001$ & 33.4 (5 to 70$)$ & $<0.0001$ \\
\hline Thoracolumbar kyphosis $\left({ }^{\circ}\right)$ & $17.5(-20$ to 70$)$ & 7.7 (-6 to 25$)$ & 0.0006 & 11.0 (-5 to 46$)$ & 0.01 \\
\hline $\operatorname{LL}\left({ }^{\circ}\right)$ & $11.5(-28$ to 50$)$ & 46.9 (32 to 67) & 0.0001 & 46.7 (23 to 67) & 0.01 \\
\hline $\mathrm{LL}$ in $\mathrm{FBB}\left({ }^{\circ}\right)$ & 36.9 (9 to 62$)$ & & & & \\
\hline Pelvic tilt $\left({ }^{\circ}\right)$ & 32.9 (16 to 64$)$ & 20.9 (12 to 34) & 0.004 & 22.5 (12 to 46) & 0.714 \\
\hline $\operatorname{PI}\left({ }^{\circ}\right)$ & 52.3 (43 to 65$)$ & - & & - & \\
\hline $\mathrm{PI}-\mathrm{LL}\left({ }^{\circ}\right)$ & 40.4 (8 to 83) & $3.3(-7$ to 14$)$ & $<0.0001$ & $5.2(-6$ to 21$)$ & 0.01 \\
\hline $\mathrm{PI}-\mathrm{LL}(\mathrm{FBB})\left(^{\circ}\right)$ & $18.2(-2$ to 46$)$ & & & & \\
\hline Sagittal vertical axis (mm) & 104.6 (10 to 180$)$ & 26.1 (-11 to 85) & $<0.0001$ & 39.0 (0 to 130$)$ & 0.10 \\
\hline
\end{tabular}

Values are presented as mean (range)

$\mathrm{LL}$, lumbar lordosis; FBB, fulcrum backward bending; PI, pelvic incidence. 
Table 4. Radiographic data comparison between patients with and without PJK

\begin{tabular}{|c|c|c|c|}
\hline Variable & PJK (n=9) & Non-PJK (n=30) & $p$-value \\
\hline Age (yr) & 73.5 (70 to 83$)$ & 65.5 (42 to 81) & 0.01 \\
\hline FRAX ${ }^{a)}$ major Fr & 22.4 (3.4 to 38.6$)$ & 11.6 (1.4 to 33.5$)$ & 0.04 \\
\hline \multicolumn{4}{|l|}{ Thoracic kyphosis } \\
\hline $\operatorname{PreO}\left({ }^{\circ}\right)$ & $20.4(-15$ to 50$)$ & $14.0(-15$ to 35$)$ & 0.43 \\
\hline $\mathrm{PO}\left({ }^{\circ}\right)$ & 32.6 (18 to 53) & 25.9 (5 to 36$)$ & 0.25 \\
\hline $\mathrm{PO} 2 \mathrm{Y}\left({ }^{\circ}\right)$ & 44.1 (25 to 70$)$ & 30.3 (5 to 47$)$ & 0.09 \\
\hline \multicolumn{4}{|l|}{ Thoracolumbar kyphosis } \\
\hline $\operatorname{PreO}\left({ }^{\circ}\right)$ & 23.1 (-20 to 70$)$ & 15.8 (-18 to 42$)$ & 0.55 \\
\hline $\mathrm{PO}\left(^{\circ}\right)$ & 11.1 (0 to 25) & $6.6(-6$ to 25$)$ & 0.18 \\
\hline $\operatorname{PO2Y}\left({ }^{\circ}\right)$ & 19.3 (5 to 48 ) & $8.4(-5$ to 26$)$ & 0.08 \\
\hline \multicolumn{4}{|l|}{$\mathrm{PI}-\mathrm{LL}$} \\
\hline $\operatorname{PreO}\left({ }^{\circ}\right)$ & 45.9 (13 to 83) & 38.8 (8 to 66 ) & 0.44 \\
\hline $\mathrm{PO}\left({ }^{\circ}\right)$ & $2.9(-4$ to 14$)$ & $3.4(-6$ to 12$)$ & 0.81 \\
\hline $\operatorname{PO2Y}\left({ }^{\circ}\right)$ & $4.9(-4$ to 19$)$ & $5.3(-6$ to 21$)$ & 0.90 \\
\hline $\mathrm{PI}-\mathrm{LL}$ in fulcrum backward bending $\left({ }^{\circ}\right)$ & 20.9 (5 to 46$)$ & 17.2 (-2 to 39$)$ & 0.51 \\
\hline \multicolumn{4}{|l|}{ Pelvic tilt } \\
\hline $\operatorname{PreO}\left({ }^{\circ}\right)$ & 38.0 (23 to 64) & 31.4 (16 to 50) & 0.20 \\
\hline $\mathrm{PO}\left({ }^{\circ}\right)$ & 22.5 (17 to 34) & 20.5 (12 to 30$)$ & 0.34 \\
\hline $\mathrm{PO2Y}\left({ }^{\circ}\right)$ & 26.5 (20 to 46) & 21.3 (15 to 38) & 0.13 \\
\hline \multicolumn{4}{|l|}{ Sagittal vertical axis } \\
\hline PreO (mm) & 125.4 (87 to 173$)$ & $98.5(10$ to 180$)$ & 0.11 \\
\hline $\mathrm{PO}(\mathrm{mm})$ & $33.9(-11$ to 85$)$ & 23.7 (0 to 70$)$ & 0.46 \\
\hline P02Y (mm) & 53.3 (0 to 130$)$ & 34.8 (0 to 165$)$ & 0.36 \\
\hline \multicolumn{4}{|l|}{ Proximal junctional angle } \\
\hline PreO $\left({ }^{\circ}\right)$ & $9.3(-2$ to 25$)$ & 14.0 (6 to25) & 0.15 \\
\hline $\operatorname{PO2Y}\left({ }^{\circ}\right)$ & $11.8(-5$ to 25$)$ & 29.9 (13 to 49) & 0.01 \\
\hline
\end{tabular}

Values are presented as mean (range).

PJK, proximal junctional kyphosis; Pre0, prior to surgery; PO, 2 weeks after surgery; P02Y, 2 years after surgery; PI, pelvic incidence; LL, lumbar lordosis.

${ }^{a}$ World Health Organization fracture risk assessment tool.

\section{1) PJK group versus non-PJK group}

The mean age at surgery in the PJK group was significantly more than that in the non-PJK group (73.5 versus 65.5 years.). Additionally, the risk of a major fracture, according to the fracture risk assessment tool (FRAX), was significantly higher in the PJK group than in the non-PJK group (22.4 versus 11.6). Comparative analysis of radiographic parameters indicated that there was a greater tendency for PO SVA, PO2Y TK, and PO2Y TLK in the PJK group than in the non-PJK group. PJA at PO2Y in the PJK group was significantly larger than that in the non-PJK group $(p=0.01)$. Table 4 summarizes these analyses. All domains of the SRS-22 scores in both the groups are shown in Table 5 , and all domains of SF-36 are shown in Table 6. No significant differences were noted between the two groups.

\section{2) TPH versus PS group}

The incidence of PJK in the TPH group was statistically comparable with that in the PS group, as already described. No significant differences were noted in any of the data including age at surgery, FRAX, and radiographic parameters (Table 7). However, the dPJA of patients with PJK was significantly larger in the PS group than in the TPH group (Table 8). 
Table 5. Surgical outcomes for the PJK and non-PJK groups: Japanese version of the Scoliosis Research Society-22 Outcomes Questionnaire

\begin{tabular}{|c|c|c|c|c|c|c|}
\hline Variable & Function/activity & Pain & Self image & Mental health & Total score & Satisfaction \\
\hline \multicolumn{7}{|c|}{ Prior to surgery } \\
\hline PJK & 2.4 & 2.7 & 2.3 & 2.4 & 2.4 & - \\
\hline Non-PJK & 2.7 & 2.7 & 2.2 & 2.7 & 2.6 & - \\
\hline$p$-value & 0.33 & 0.92 & 0.57 & 0.44 & 0.68 & - \\
\hline \multicolumn{7}{|c|}{2 Years after surgery } \\
\hline PJK & 3.5 & 4.1 & 3.4 & 3.8 & 3.7 & 3.9 \\
\hline Non-PJK & 3.8 & 4.1 & 3.8 & 3.8 & 3.9 & 4.1 \\
\hline$p$-value & 0.25 & 0.98 & 0.26 & 0.91 & 0.51 & 0.64 \\
\hline
\end{tabular}

PJK, proximal junctional kyphosis.

Table 6. Surgical outcomes for the PJK and non-PJK groups: health-related quality of life outcomes measured with the Medical Outcomes Study Questionnaire Short-Form 36

\begin{tabular}{lcccccccc} 
Variable & PF & RP & BP & GH & VT & SF & RE & MH \\
$\begin{array}{l}\text { Prior to surgery } \\
\text { PJK }\end{array}$ & 31.7 & 25.8 & 37.5 & 35.5 & 23.5 & 32.9 & 32.3 & 35.0 \\
$\quad$ Non-PJK & 45.6 & 44.5 & 37.0 & 44.6 & 44.7 & 58.3 & 54.6 & 53.3 \\
$\quad p$-value & 0.18 & 0.16 & 0.97 & 0.24 & 0.006 & 0.008 & 0.14 & 0.03 \\
\hline Years after surgery & & & & & & & & \\
\hline PJK & 61.9 & 75.9 & 55.3 & 59.3 & 71.7 & 67.2 & 79.8 & 76.3 \\
$\quad$ Non-PJK & 65.0 & 69.7 & 62.0 & 59.6 & 57.4 & 76.4 & 72.2 & 68.1 \\
\hline$p$-value & 0.79 & 0.64 & 0.60 & 0.96 & 0.11 & 0.57 & 0.63 & 0.26 \\
\hline
\end{tabular}

PJK, proximal junctional kyphosis.

${ }^{a}$ The Short-Form 36 comprises eight health scales: physical functioning (PF), role limitations caused by physical problems (RP), bodily pain (BP), general health perceptions (GH), vitality (VT), social functioning (SF), role limitations caused by emotional problems (RE), and mental health (MH).

\section{Discussion}

PJK is a recognized complication following ASD surgery and has recently attracted increased attention [7-11,1618]. PJK had been defined as a change in PJA of $>10^{\circ}$ [24]. However, some studies have indicated that these changes do not affect clinical outcomes. Bridwell et al. [25] evaluated PJK following ASD surgery using PJA $>20^{\circ}$ and found that the clinical outcomes were worse in patients with PJK. Yagi et al. $[10,18]$ classified PJK into three types: ligamentous failure, bone failure, and implant/bone interface failure. Therefore, in the present study, changes in PJA of $>20^{\circ}$ and the presence of UIV or UIV \pm 1 fracture were used to define PJK. The incidence of PJK in the current study was $24 \%$ (9/37), and eight of the nine PJK patients showed bone failure, including UIV fracture and UIV-1 fracture. Six UIV fractures occurred within
4 weeks after surgery. Several previous reports have cited PJK incidence ranging from $20 \%$ to $40 \%$ [8]. Yagi et al. [10] reported that $76 \%$ of PJK occurred within 3 months after surgery [10], and Maruo et al. [17] reported that $62 \%$ of PJK occurred within 8 weeks after surgery [17]. They also stated that UIV fracture was the most common mechanism of PJK. Our results approximately matched their results. Therefore, we believe that UIV fracture is the most common etiology of PJK and that it occurs relatively early after ASD surgery.

Several risk factors of PJK, including older age $[11,17,18]$, spinopelvic fusion $[6,18,26]$, magnitude of sagittal imbalance [10], magnitude of TK [17], and a greater PI-LL change [17] have been previously reported. Recently, Scheer et al. [26] of the Invasive Species Specialist Group reported a computer-based preoperative predictive model for proximal junctional failure (PJF). The seven 
Table 7. Data comparison between surgery with TPH and PS

\begin{tabular}{|c|c|c|c|}
\hline Variable & $\mathrm{TPH}(\mathrm{n}=17)$ & $P S(n=22)$ & $p$-value \\
\hline Age (yr) & 69.3 (46 to 81) & 65.5 (42 to 83) & 0.35 \\
\hline FRAX ${ }^{a)}$ major Fr & 14.5 (1.8 to 33.5$)$ & 14.2 (1.4 to 38.6$)$ & 0.93 \\
\hline \multicolumn{4}{|l|}{ Thoracic kyphosis } \\
\hline PreO $\left({ }^{\circ}\right)$ & $15.3(-10$ to 35$)$ & $15.6(-15$ to 50$)$ & 0.95 \\
\hline $\mathrm{PO}\left({ }^{\circ}\right)$ & 27. 3 (18 to 34$)$ & 27.5 (5 to 52$)$ & 0.25 \\
\hline $\operatorname{PO2Y}\left({ }^{\circ}\right)$ & 32.5 (20 to 47) & 34.2 (5 to 70$)$ & 0.69 \\
\hline \multicolumn{4}{|l|}{ Thoracolumbar kyphosis } \\
\hline $\operatorname{PreO}\left({ }^{\circ}\right)$ & $13.9(-18$ to 42$)$ & $20.2(-20$ to 70$)$ & 0.33 \\
\hline $\mathrm{PO}\left({ }^{\circ}\right)$ & $7.0(-6$ to 25$)$ & 8.2 (0 to 25) & 0.61 \\
\hline $\operatorname{PO2Y}\left({ }^{\circ}\right)$ & $9.9(-5$ to 26$)$ & 11.7 (2 to 48$)$ & 0.57 \\
\hline \multicolumn{4}{|l|}{$\mathrm{Pl}-\mathrm{LL}$} \\
\hline Pre0 $\left(^{\circ}\right)$ & 45.3 (8 to 83) & 38.8 (13 to 69$)$ & 0.15 \\
\hline $\mathrm{PO}\left({ }^{\circ}\right)$ & $3.6(-6$ to 12$)$ & $3.1(-2$ to 14$)$ & 0.76 \\
\hline $\operatorname{PO2Y}\left({ }^{\circ}\right)$ & $6.1(-6$ to 21$)$ & $4.5(-4$ to 19$)$ & 0.49 \\
\hline $\mathrm{PI}-\mathrm{LL}$ in fulcrum backward bending $\left(^{\circ}\right)$ & 18.8 (8 to 46$)$ & $17.5(-2$ to 39$)$ & 0.72 \\
\hline \multicolumn{4}{|l|}{ Pelvic tilt } \\
\hline PreO $\left({ }^{\circ}\right)$ & 35.4 (20 to 48$)$ & 31.1 (16 to 64) & 0.18 \\
\hline $\mathrm{PO}\left({ }^{\circ}\right)$ & 21.5 (16 to 30$)$ & 20.6 (12 to 34$)$ & 0.51 \\
\hline $\operatorname{PO2Y}\left({ }^{\circ}\right)$ & 22.9 (15 to 38$)$ & 22.3 (12 to 46$)$ & 0.78 \\
\hline \multicolumn{4}{|l|}{ Sagittal vertical axis } \\
\hline Pre0 (mm) & 117.1 (15 to 180$)$ & $98.5(10$ to 180$)$ & 0.18 \\
\hline $\mathrm{PO}(\mathrm{mm})$ & $27.9(0$ to 85$)$ & $24.7(-11$ to 80$)$ & 0.70 \\
\hline $\mathrm{PO2Y}(\mathrm{mm})$ & 36.7 (0 to 130$)$ & 39.3 (0 to 165$)$ & 0.96 \\
\hline \multicolumn{4}{|l|}{ PJA } \\
\hline PreO $\left(^{\circ}\right)$ & $10.7(-2$ to 25$)$ & 9.9 (1 to 25$)$ & 0.72 \\
\hline $\operatorname{P02Y}\left({ }^{\circ}\right)$ & $14.4(-5$ to 28$)$ & 17.8 (2 to 49$)$ & 0.38 \\
\hline Change in PJA $\left(^{\circ}\right)$ & $3.7(-3$ to 25$)$ & $7.9(0$ to 35$)$ & 0.12 \\
\hline \multicolumn{4}{|l|}{ L-Cobb } \\
\hline $\operatorname{PreO}\left({ }^{\circ}\right)$ & 43.9 (24 to 67) & 47.8 (17 to 86) & 0.14 \\
\hline $\mathrm{PO}\left({ }^{\circ}\right)$ & $16.9(10$ to 30$)$ & 18.0 (2 to 37$)$ & 0.51 \\
\hline $\operatorname{PO2Y}\left({ }^{\circ}\right)$ & 17.5 (10 to 30) & 18.4 (2 to 38$)$ & 0.58 \\
\hline Lumbar curve flexibility (\%) & 35.7 (11 to 57) & 32.6 (12 to 61$)$ & 0.53 \\
\hline \multicolumn{4}{|l|}{ Coronal vertical axis } \\
\hline PreO (mm) & $24.1(0$ to 67$)$ & 25.6 (0 to 85) & 0.72 \\
\hline $\mathrm{PO}(\mathrm{mm})$ & 13.5 (0 to 43$)$ & $11.4(0$ to 40$)$ & 0.44 \\
\hline $\mathrm{PO} Y \mathrm{Y}(\mathrm{mm})$ & 12.3 (0 to 43) & $9.9(0$ to 40$)$ & 0.35 \\
\hline
\end{tabular}

Values are presented as mean (range).

TPH, transverse process hook; PS, pedicle screw; Pre0, prior to surgery; PO, 2 weeks after surgery; P02Y, 2 years after surgery; PI, pelvic incidence; $\mathrm{LL}$, lumbar lordosis; PJA, proximal junctional angle.

${ }^{a}$ World Health Organization fracture risk assessment tool.

strongest predictors of PJF are age, lowest instrumented vertebra, preoperative SVA, UIV implant type, UIV, pre- operative PT, and preoperative PI-LL. Our comparative analysis indicates that older age $(p=0.01)$ and fracture risk 
Table 8. Changes in PJA of patients with PJK between TPH and PS groups

\begin{tabular}{lccc} 
PJA & Prior to surgery & 2 Years after surgery & Change in PJA \\
TPH $(n=3)$ & $15.5^{\circ}\left(3^{\circ}-20^{\circ}\right)$ & $20.5^{\circ}\left(13^{\circ}-28^{\circ}\right)$ & $5.0^{\circ}\left(2^{\circ}-22^{\circ}\right)$ \\
$P S(n=6)$ & $13.5^{\circ}\left(6^{\circ}-25^{\circ}\right)$ & $33.0^{\circ}\left(15^{\circ}-49^{\circ}\right)$ & $19.5^{\circ}\left(8^{\circ}-35^{\circ}\right)$ \\
\hline$p$-value & 0.75 & 0.30 & 0.04 \\
\hline
\end{tabular}

Values are presented as mean (range).

PJA, proximal junctional angle; TPH, transverse process hook; PS, pedicle screw.
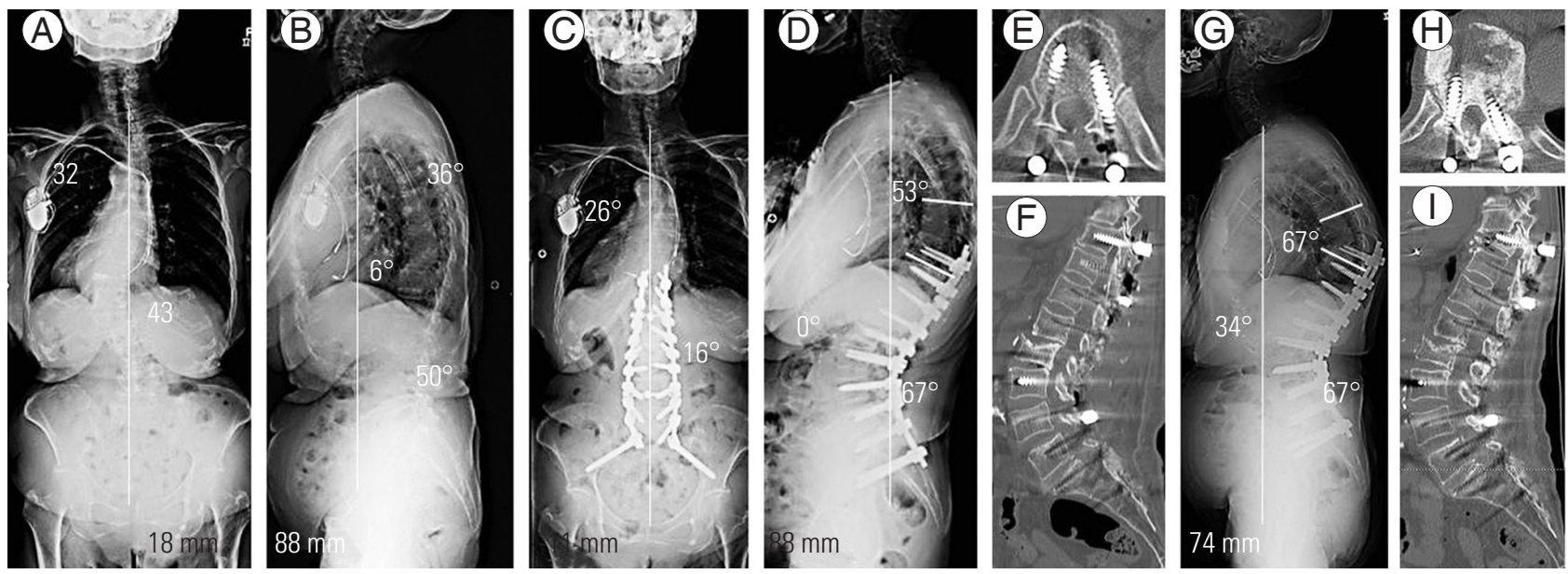

Fig. 1. Case presentation: an 83-year-old woman who underwent T10 pelvic posterior corrective surgery using PS as UIV anchor. (A, B) Preoperative radiographs. AP radiograph shows that the Cobb angle of the lumbar curve and the compensatory thoracic curve were $26^{\circ}$ and $43^{\circ}$, respectively. Lateral radiograph shows TK of $36^{\circ}$, TLK of $6^{\circ}$, LL of $50^{\circ}$, PT of $23^{\circ}$, and PI of $63^{\circ}$. PI-LL was $13^{\circ}$. SVA shifted $88 \mathrm{~mm}$ anteriorly. (C, D) Radiographs 2 weeks after surgery. AP radiograph shows a Cobb angle of the compensatory thoracic and lumbar spine reduced to $26^{\circ}$ and $16^{\circ}$, respectively. Lateral radiograph shows TK of $53^{\circ}$, TLK of $0^{\circ}$, LL of $67^{\circ}$, and PT of $22^{\circ}$. PI-LL was reduced to $-4^{\circ}$, and SVA was improved to $-11 \mathrm{~mm}$. (E, F) CT images 1 week after surgery showing no apparent fracture at UIV. However, UIV fracture occurred 1 month after surgery with progression of segmental kyphosis. (G) Radiograph 3 years after surgery. Lateral radiograph shows TK of $67^{\circ}$, TLK of $34^{\circ}$, LL of $67^{\circ}$, PT of $22^{\circ}$, and SVA deteriorated to $74 \mathrm{~mm}$. Proximal junctional angle changed from $12^{\circ}$ before surgery to $34^{\circ}$ at 3 years after surgery. (H, I) CT images show vertebral collapse of UIV and PS penetration of the disc space. PS, pedicle screw; UIV, upper instrumented vertebrae; AP, anteroposterior; TK, thoracic kyphosis; TLK, thoracolumbar kyphosis; LL, lumbar lordosis; PT, pelvic tilt; PI, pelvic incidence; SVA, sagittal vertical axis; CT, computed tomography.

defined by FRAX ( $p=0.04)$ are possible risk factors of PJK. Preoperative SVA $(p=0.11)$ shows some tendency in that regard.

According to previous reports, the impact of PJK on quality of life is variable $[9,18]$. However, the severity of PJK may vary, and PJF may result in compromised structural integrity and neurological deficit, with severe cases potentially needing revision surgery $[10,11]$. Unlike PJK, patients with PJF have a worse clinical course. The current comparative analysis of health-related quality of life between PJK and non-PJK shows that PJK has no significant impact on surgical outcomes. It may be because none of the patients had a neurological deficit and radiographic measurements improved in all patients with PJK.

Preventing PJK in patients who undergo ASD surgery is one of the most important issues for successful correction surgery and improvement in the postoperative quality of life [26]. As described, PJK is a multifactorial phenomenon that may occur after long-segment fixation surgery. Therefore, there is no definitive solution for preventing $\mathrm{PJK}$, although there are some prophylactic procedures. Some reported strategies are the treatment of osteoporosis with teriparatide [20]; surgical intervention including cement augmentation [13], UIV anchors [21,22], and percutaneous screws [27]; transitional rods [28]; UIV selection [13-15]; and preservation of the posterior ligamentous complex [16].

Among these strategies, we were particularly interested in the types of UIV anchors. The comparative analysis of TPH and PS as UIV anchors indicates no significant difference in the incidence of PJK. However, changes in PJA in patients with PJK were significantly more common in 

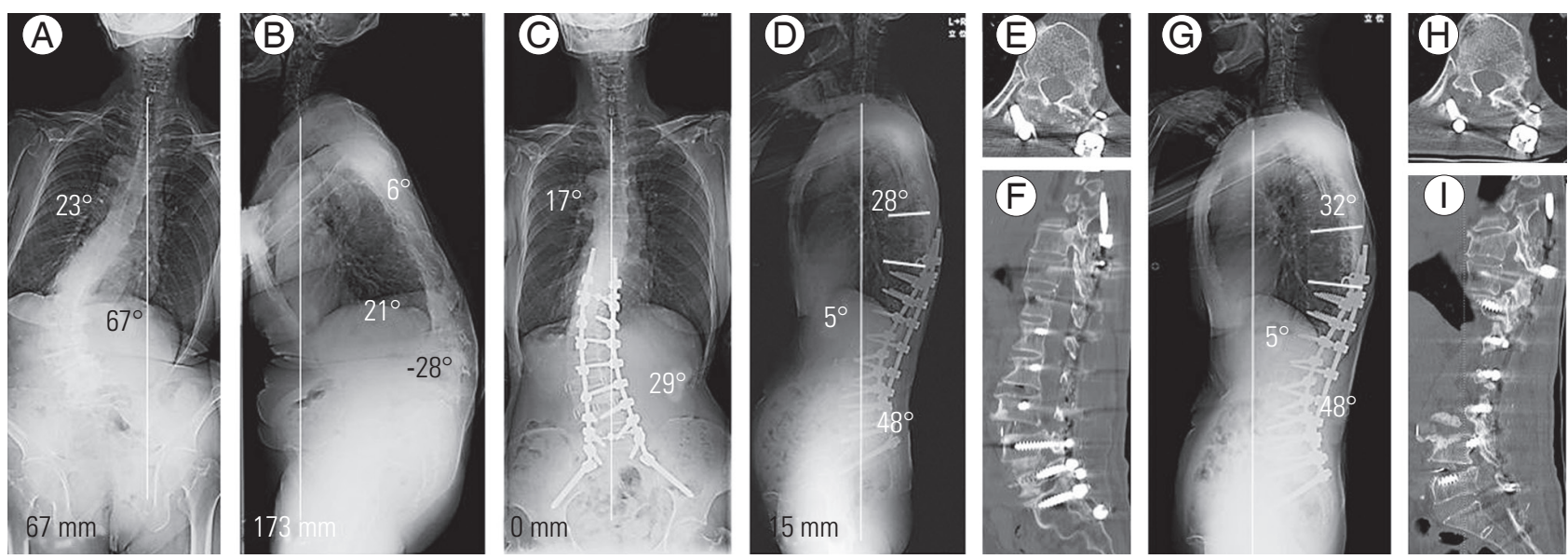

Fig. 2. Case presentation: A 75-year-old woman who underwent T10 pelvic lateral interbody fusion and posterior corrective surgery using transverse process hook as UIV anchor. (A, B) Preoperative radiographs. AP radiograph shows that the Cobb angle of the lumbar curve and the compensatory thoracic curve were $23^{\circ}$ and $67^{\circ}$, respectively. Lateral radiograph shows TK of $6^{\circ}$, TLK of $21^{\circ}$, LL of $-28^{\circ}, \mathrm{PT}$ of $45^{\circ}$, and $\mathrm{PI}$ of $55^{\circ}$. PI- $\mathrm{LL}$ was $83^{\circ}$. SVA shifted $173 \mathrm{~mm}$ anteriorly. (C, D) Radiographs 2 weeks after surgery. AP radiograph shows that Cobb angle of the compensatory thoracic and lumbar spine reduced to $17^{\circ}$ and $16^{\circ}$, respectively. Lateral radiograph shows TK of $28^{\circ}$, TLK of $6^{\circ}$, $\mathrm{LL}$ of $48^{\circ}$, and PT of $26^{\circ}$. PI- $\mathrm{LL}$ was reduced to $7^{\circ}$, and SVA improved to $15 \mathrm{~mm}$. (E, F) CT images 1 week after surgery show no apparent fracture at UIV. However, UIV fracture occurred 3 weeks after surgery but without progression of segmental kyphosis. (G) Radiographs 3 years after surgery. Lateral radiograph shows $\mathrm{TK}^{\mathrm{a}} 32^{\circ}, \mathrm{TLK}^{\circ}$ of $6^{\circ}, \mathrm{LL}$ of $48^{\circ}$, PT of $26^{\circ}$, and no deterioration of SVA. Proximal junctional angle changed from $11^{\circ}$ before surgery to $13^{\circ}$ at 3 years after surgery. ( $\left.\mathrm{H}, \mathrm{I}\right) \mathrm{CT}$ images show that the vertebral collapse of UIV is acceptable and that the endplate of UIV is intact. CT, computed tomography. UIV, upper instrumented vertebrae; AP, anteroposterior; TK, thoracic kyphosis; TLK, thoracolumbar kyphosis; LL, lumbar lordosis; PT, pelvic tilt; PI, pelvic incidence; SVA, sagittal vertical axis; CT, computed tomography.

the PS group (Fig. 1) than in the TPH group (Fig. 2). The magnitude of vertebral body collapse following vertebral fracture was more severe in the PS group. Watanabe at al. [11] reported proximal junctional vertebral fracture following ASD surgery that used PS constructs. Additionally, a comparative study of adolescent idiopathic scoliosis surgery indicated significant advantages for TPH over PS fixation to prevent PJK [21,22]. In a biomechanical study, TPH fixation produced a significant reduction of flexion movement compared to PS fixation [15]. Our results were consistent with these reports. We speculate that the mechanism of PJK using PS as the UIV anchor may be as follows. In the patient with osteoporosis, PS as the UIV anchor may directly damage the vertebral body, allowing subsequent vertebral fracture. If a fracture occurs, PS may break the upper endplate and penetrate the disc space, leading to severe collapse of UIV. Conversely, TPH as the UIV anchor may be a better choice because it provides a soft landing at the transitional segment of the long-segment fixation construct [29]. There are some limitations to our study. Our study included a small number of cases and had a short-term follow-up period, and this was not a biomechanical study. Future work should involve a longer follow-up period and a larger sample size.

\section{Conclusions}

Our results show that using TPH as a UIV implant may not prevent PJK; however, using TPH as the UIV anchor may prevent vertebral collapse if cases of UIV fracture. In this study, the increased risk of collapse with UIV fracture in the PS group may have been the result of a higher mechanical load on UIV when using PS fixation. Further biomechanical studies should be performed to clarify our results.

\section{Conflict of Interest}

No potential conflict of interest relevant to this article was reported.

\section{Author Contributions}

Matsumura A: corresponding author, conception, design, and analysis; Matsumura A, Namikawa T, Kato M, Oyama S, Ozaki T, Hori Y, Yabu A: acquisition of data; and Hidaka N, Nakamura H: critically revising the article. 


\section{References}

1. Schwab F, Lafage V, Patel A, Farcy JP. Sagittal plane considerations and the pelvis in the adult patient. Spine (Phila Pa 1976) 2009;34:1828-33.

2. Boachie-Adjei O, Dendrinos GK, Ogilvie JW, Bradford DS. Management of adult spinal deformity with combined anterior-posterior arthrodesis and Luque-Galveston instrumentation. J Spinal Disord 1991;4:131-41.

3. Tsuchiya K, Bridwell KH, Kuklo TR, Lenke LG, Baldus C. Minimum 5-year analysis of L5-S1 fusion using sacropelvic fixation (bilateral S1 and iliac screws) for spinal deformity. Spine (Phila Pa 1976) 2006;31:303-8.

4. Kim YJ, Bridwell KH, Lenke LG, Rhim S, Cheh G. Pseudarthrosis in long adult spinal deformity instrumentation and fusion to the sacrum: prevalence and risk factor analysis of 144 cases. Spine (Phila Pa 1976) 2006;31:2329-36.

5. Banno T, Hasegawa T, Yamato Y, et al. Prevalence and risk factors of iliac screw loosening after adult spinal deformity surgery. Spine (Phila Pa 1976) 2017;42:E1024-30.

6. Kebaish KM. Sacropelvic fixation: techniques and complications. Spine (Phila Pa 1976) 2010;35:224551.

7. Lau D, Clark AJ, Scheer JK, et al. Proximal junctional kyphosis and failure after spinal deformity surgery: a systematic review of the literature as a background to classification development. Spine (Phila Pa 1976) 2014;39:2093-102.

8. Scheer JK, Fakurnejad S, Lau D, et al. Results of the 2014 SRS survey on PJK/PJF: a report on variation of select SRS member practice patterns, treatment indications, and opinions on classification development. Spine (Phila Pa 1976) 2015;40:829-40.

9. Kim HJ, Bridwell KH, Lenke LG, et al. Proximal junctional kyphosis results in inferior SRS pain subscores in adult deformity patients. Spine (Phila Pa 1976) 2013;38:896-901.

10. Yagi M, Rahm M, Gaines R, et al. Characterization and surgical outcomes of proximal junctional failure in surgically treated patients with adult spinal deformity. Spine (Phila Pa 1976) 2014;39:E607-14.

11. Watanabe K, Lenke LG, Bridwell KH, Kim YJ, Koester L, Hensley M. Proximal junctional vertebral frac- ture in adults after spinal deformity surgery using pedicle screw constructs: analysis of morphological features. Spine (Phila Pa 1976) 2010;35:138-45.

12. O'Leary PT, Bridwell KH, Lenke LG, et al. Risk factors and outcomes for catastrophic failures at the top of long pedicle screw constructs: a matched cohort analysis performed at a single center. Spine (Phila Pa 1976) 2009;34:2134-9.

13. Hart RA, Prendergast MA, Roberts WG, Nesbit GM, Barnwell SL. Proximal junctional acute collapse cranial to multi-level lumbar fusion: a cost analysis of prophylactic vertebral augmentation. Spine J 2008;8:875-81.

14. Kim YJ, Bridwell KH, Lenke LG, Rhim S, Kim YW. Is the $\mathrm{T} 9, \mathrm{~T} 11$, or $\mathrm{L} 1$ the more reliable proximal level after adult lumbar or lumbosacral instrumented fusion to L5 or S1? Spine (Phila Pa 1976) 2007;32:265361.

15. Cammarata M, Aubin CE, Wang X, Mac-Thiong JM. Biomechanical risk factors for proximal junctional kyphosis: a detailed numerical analysis of surgical instrumentation variables. Spine (Phila Pa 1976) 2014;39:E500-7.

16. Hostin R, McCarthy I, O'Brien M, et al. Incidence, mode, and location of acute proximal junctional failures after surgical treatment of adult spinal deformity. Spine (Phila Pa 1976) 2013;38:1008-15.

17. Maruo K, Ha Y, Inoue S, et al. Predictive factors for proximal junctional kyphosis in long fusions to the sacrum in adult spinal deformity. Spine (Phila $\mathrm{Pa}$ 1976) 2013;38:E1469-76.

18. Yagi M, Akilah KB, Boachie-Adjei O. Incidence, risk factors and classification of proximal junctional kyphosis: surgical outcomes review of adult idiopathic scoliosis. Spine (Phila Pa 1976) 2011;36:E60-8.

19. Kim HJ, Yagi M, Nyugen J, Cunningham ME, Boachie-Adjei O. Combined anterior-posterior surgery is the most important risk factor for developing proximal junctional kyphosis in idiopathic scoliosis. Clin Orthop Relat Res 2012;470:1633-9.

20. Yagi M, Ohne H, Konomi T, et al. Teriparatide improves volumetric bone mineral density and fine bone structure in the UIV+1 vertebra, and reduces bone failure type PJK after surgery for adult spinal deformity. Osteoporos Int 2016;27:3495-502.

21. Helgeson MD, Shah SA, Newton PO, et al. Evaluation of proximal junctional kyphosis in adolescent 
idiopathic scoliosis following pedicle screw, hook, or hybrid instrumentation. Spine (Phila Pa 1976) 2010;35:177-81.

22. Kim YJ, Lenke LG, Bridwell KH, et al. Proximal junctional kyphosis in adolescent idiopathic scoliosis after 3 different types of posterior segmental spinal instrumentation and fusions: incidence and risk factor analysis of 410 cases. Spine (Phila Pa 1976) 2007;32:2731-8.

23. Cheung KM, Luk KD. Prediction of correction of scoliosis with use of the fulcrum bending radiograph. J Bone Joint Surg Am 1997;79:1144-50.

24. Glattes RC, Bridwell KH, Lenke LG, Kim YJ, Rinella A, Edwards C 2nd. Proximal junctional kyphosis in adult spinal deformity following long instrumented posterior spinal fusion: incidence, outcomes, and risk factor analysis. Spine (Phila Pa 1976) 2005;30:1643-9.

25. Bridwell KH, Lenke LG, Cho SK, et al. Proximal junctional kyphosis in primary adult deformity surgery: evaluation of 20 degrees as a critical angle. Neurosurgery 2013;72:899-906.
26. Scheer JK, Osorio JA, Smith JS, et al. Development of validated computer-based preoperative predictive model for proximal junction failure (PJF) or clinically significant PJK with $86 \%$ accuracy based on 510 ASD patients with 2-year follow-up. Spine (Phila Pa 1976) 2016;41:E1328-35.

27. Mummaneni PV, Park P, Fu KM, et al. Does minimally invasive percutaneous posterior instrumentation reduce risk of proximal junctional kyphosis in adult spinal deformity surgery?: a propensitymatched cohort analysis. Neurosurgery 2016;78:1018.

28. Cahill PJ, Wang W, Asghar J, et al. The use of a transition rod may prevent proximal junctional kyphosis in the thoracic spine after scoliosis surgery: a finite element analysis. Spine (Phila Pa 1976) 2012;37:E68795.

29. Bess S, Harris JE, Turner AW, et al. The effect of posterior polyester tethers on the biomechanics of proximal junctional kyphosis: a finite element analysis. J Neurosurg Spine 2017;26:125-33. 